\title{
Clinical Characteristics of Paediatric Hyperinflammatory Syndrome in the Era of Corona Virus Disease 2019 (COVID-19)
}

\author{
Manjari Basu ${ }^{1} \cdot$ Subir Kumar $\operatorname{Das}^{2}$ (D)
}

Received: 15 August 2020/ Accepted: 17 February 2021 / Published online: 6 March 2021

(C) Association of Clinical Biochemists of India 2021

\begin{abstract}
The pandemic of COVID-19 initially appeared to cause only a mild illness in children. However, it is now apparent that a small percentage of children can develop a hyperinflammatory syndrome labeled as Pediatric inflammatory multisystem syndrome-temporally associated with SARS-CoV-2 (PIMS-TS) with a phenotype resembling Kawasaki disease (KD) ('Kawa-COVID-19'). Features of this newly recognized condition may include fever, hypotension, severe abdominal pain and cardiac dysfunction, evidence of inflammation, and single or multi organ dysfunction in the absence of other known infections. Children emerge to have mild symptoms compared to adults, perhaps due to reduced expression of the angiotensin converting enzyme (ACE)-2 receptor (the target of SARS-CoV-2) gene, trained innate immunity, and a young and fit immune system. Some of these children may share features of Kawasaki disease, toxic shock syndrome or cytokine storm syndrome. They can deteriorate rapidly and may need intensive care support as well. The PCR test is more often negative although most of the children have antibodies to SARS-CoV-2. Although the pathogenesis is not clearly known, immune-mediated injury has been implicated.
\end{abstract}

Subir Kumar Das

drsubirkdas@yahoo.co.in

1 Department of Paediatrics, College of Medicine and JNM Hospital, WBUHS Kalyani, Nadia 741235, West Bengal, India

2 Department of Biochemistry, College of Medicine and JNM Hospital, WBUHS Kalyani, Nadia 741235, West Bengal, India
Keywords Angiotensin converting enzyme - COVID-19 . Hyperinflammatory syndrome · Kawasaki Disease . Pediatric inflammatory multisystem syndrome $\cdot$ SARSCoV-2

\section{Introduction}

When the COVID-19 pandemic was first reported in a market place in Wuhan, China and multiplied throughout the world, paediatricians were appreciative that children appeared apparently mildly symptomatic with the contagion in most cases [1]. The first case of a child with Kawaski disease (KD) and concurrent COVID-19 was reported in the United States on the 7th April, 2020 [2]. Physicians from the UK reported a cluster of children with unexplained inflammation necessitating support of paediatric intensive care units (PICUs) in April, 2020 [3]. Meanwhile seventeen children with signs and symptoms adhering with Kawasaki disease (KD) and laboratory proof of recent SARS-CoV-2 infection were described in the United States $(\mathrm{n}=1)$, England $(\mathrm{n}=8)$, and Italy $(\mathrm{n}=8)$ $[2,4,5]$. Data imply that COVID-19 is commonly mild and self-limiting in previously healthy children, but they may emerge severe disease $[6,7]$. This ailment is named paediatric inflammatory multisystem syndrome temporally associated with SARS-CoV-2 infection (PIMS-TS) in Europe [8] and multisystem inflammatory syndrome in children (MIS-C) in the United States [9]. Additionally, a case report of such involvement and a few paediatric sequence of hyperinflammatory shock during COVID-19 pandemic have been published $[2,4,5,10]$. Another case series from Bergamo, Italy, an area with high prevalence of COVID-19 disease, reported a 30-fold enhancement in the monthly incidence of $\mathrm{KD}$ cases between mid-February 
2020 and mid-April 2020 in comparison to the preceding 5 years [5]. The New York State Department of Health (NYSDOH) informed 102 apparent cases of MIS-C on the 13 May 2020, after the peak of COVID-19 infection in early April [11]. A case series of 58 children from 8 hospitals in England reported hospitalization between March 23 and May 16, 2020, with continual fever and laboratory proof of inflammation fulfilled published classifications for PIMS-TS [12]. Interestingly, the bunch of MIS-C cases in these places lags behind the peak COVID-19 occurrence among adults by about one month [13]. A handful number of hospitalized cases in infants and children were reported compared to adults in hospitals in Navarra, Spain during the first wave of the COVID-19 outbreak (February-May 2020) [14]. Ten febrile children were hospitalised with COVID-19 infection demonstrating characteristics of PIMS in northern Iran from 28th March to 24th June 2020 [15]. First such case in India was reported from Chennai on the 10th May, 2020 [16]. The second case from India was reported from Kolkata, West Bengal on the 22nd May, 2020 [17]. Fourteen cases of PIMS-TS including a 4 months old healthy baby were treated till the first week of August 2020 in Kolkata, West Bengal [17]. Thus, children of all ages appeared vulnerable to COVID-19, and there was no significant gender difference [18].

A total of 570 U.S. MIS-C patients had been reported to Centre for Disease control and Prevention, USA (CDC) as of July 29. Among them, 203 patients had clinical symptoms similar to previously published MIS-C reports, and the remaining 367 patients had symptoms that emerged to be related with acute COVID-19 [19]. Interestingly, total number of COVID-19 positive cases in US on July 29 was $4,328,695$ [20]. It appears that due to the mild presentation of the disease in children, they are less likely to be tested [21]. In one study, the literature review divulged 36 articles unfolding 320 children with Kawasaki-like disease related with COVID-19 [22]. In another study, two independent authors screened articles on MIS-C from January 1st, 2020 to July 25th, 2020 from four medical databases, and identified 39 observational studies with 662 patients [23]. Retrieving systematic reviews and metaanalyses guidelines from a total of 328 articles published from January 1, 2020, to July 31,$2020 ; 16$ studies with 655 participants were incorporated in the final analysis [24]. In another study among 44,762 laboratory-authenticated cases from China, only $416(1 \%)$ and $549(1 \%)$ were from age-groups $<10$ and 10-19 y, respectively [25]. Likewise, out of 32,437 positive laboratory examinations in the USA, $168(0.5 \%)$ and $425(1.3 \%)$ were the $0-4$ and 5-17 y age-group, respectively. Test positivity rates among total tests were 3.9 and $6.3 \%$ in $0-4$ and $5-17$ y age groups, in contrast to overall $14.4 \%$ positivity rates [26].

\section{Features}

Interestingly, features of this newly recognized disease is emerging. International health organizations had issued guidelines related to a PIMS-TS/MIS-C at the end of April 2020 and beginning of May 2020 (Table 1) [27-29].

Important observations of this syndrome include fever, abdominal pain, diarrhea, shock, and variable presence of rash, conjunctivitis, extremity edema, mucous membrane changes [30], cheilitis and adenitis [31]. Inflammation to myocardial injury, shock and development of coronary artery dilatation or aneurysms varies from other pediatric inflammatory conditions [12]. A few patients reported exclusive central nervous system contribution with small vessel vasculitis and intense hypocomplementemia [32]. Arterial hypotension with primarily vasoplegic clinical presentation may be observed in critically sick children [31].

Though some study inferred that children have fewer comorbidities for this syndrome include asthma and overweight [10], however other study did not support the hypothesis that overweight as a risk factor [33].

\section{Laboratory Investigations}

The majority of patients exhibited with low or negative nasal SARS-CoV-2 viral load, with a little residual stool excretion as reported by RT-PCR [6], while positive IgG antibody detection reported in most cases $[12,33]$. In the previously mentioned review of different studies reported that SARS-CoV-2 RT-PCR was negative in 120 (65.5\%) of 183 patients, while the serology was positive in 130 $(83.8 \%)$ of 155 patients [22].

Collectively laboratory examinations expressed the significant elevation of inflammatory markers, for example, C-reactive protein (CRP), erythrocyte sedimentation rate (ESR), procalcitonin, and/or ferritin [12], as well cytokine storm [interleukin (IL)-6] [10]. Other conventional findings include hyponatremia, acute kidney injury (elevated serum creatinine), and abnormal liver function (hypoalbuminemia) [34]. Serous effusions (pleural, pericardial, and peritoneal) in several patients are suggestive of widespread inflammation [13]. Elevated levels of troponin I, creatinine kinase (CK) and pro-B-type natriuretic peptide (proBNP), are associated with myocardial damage or heart failure [13]. Affected children also reported with increased level of procalcitonin $(>1.6 \mathrm{ng} / \mathrm{mL})$ without other microbial infection [31].

Hematologic anomalies included neutrophilia, lymphopenia, low to normal platelet levels, elevated D-dimer, and low fibrinogen [13]. Lymphocytic and myeloid 
Table 1 Paediatric Case Definitions for Emerging Inflammatory Condition During COVID-19 Pandemic From the World Health Organization, Royal College of Paediatrics and Child Health, and Centers for Disease Control and Prevention

\begin{tabular}{|c|c|c|}
\hline World Health Organization [27] & $\begin{array}{l}\text { Royal College of Paediatrics and Child Health } \\
\text { (United Kingdom) [28] }\end{array}$ & $\begin{array}{l}\text { Centers for Disease Control and Prevention } \\
\text { (United States) [29] }\end{array}$ \\
\hline $\begin{array}{l}\text { Age } \leq 19 \text { y with fever }>3 \mathrm{~d} \\
\text { AND } \\
\text { Two of the following: } \\
\text { Rash or bilateral nonpurulent conjunctivitis or } \\
\text { mucocutaneous inflammation signs (oral, } \\
\text { hands, or feet) } \\
\text { Hypotension or shock } \\
\text { Features of myocardial dysfunction, } \\
\text { pericarditis, valvulitis, or coronary } \\
\text { abnormalities (ECHO findings or elevated } \\
\text { troponin/ NT-proBNP) } \\
\text { Proof of coagulopathy } \\
\text { (PT, APTT, elevated D-dimers) } \\
\text { Acute gastrointestinal problems } \\
\text { (diarrhea, vomiting, or abdominal pain) } \\
\text { AND } \\
\text { Elevated inflammation markers (ESR, CRP, or } \\
\text { procalcitonin) } \\
\text { AND }\end{array}$ & $\begin{array}{l}\text { A child presenting with } \\
\text { Persistent fever, } \\
\text { Inflammation (neutrophilia, elevated CRP, and } \\
\text { lymphopenia) } \\
\text { Evidence of single or multiorgan dysfunction } \\
\text { (shock, cardiac, respiratory, kidney, } \\
\text { gastrointestinal, or neurological disorder) } \\
\text { with } \\
\text { Additional features include fulfilling full or } \\
\text { partial criteria for Kawasaki disease } \\
\text { Exclusion of any other microbial cause, } \\
\text { including bacterial sepsis, staphylococcal or } \\
\text { streptococcal shock syndromes, infections } \\
\text { associated with myocarditis such as } \\
\text { enterovirus } \\
\text { SARS-CoV-2 PCR test results may be positive } \\
\text { or negative }\end{array}$ & $\begin{array}{l}\text { Individual aged }<21 \mathrm{y} \\
\text { presenting with fever, } \\
\text { Fever }>38.0{ }^{\circ} \mathrm{C} \text { for } \geq 24 \mathrm{~h} \text { or report of } \\
\text { subjective } \\
\text { fever lasting } \geq 24 \mathrm{~h} \\
\text { Laboratory evidence of inflammation, as well } \\
\geq 1 \text { of the following: } \\
\text { (elevated CRP level, ESR, fibrinogen, } \\
\text { procalcitonin, D-dimer, ferritin, lactic acid } \\
\text { dehydrogenase, or IL-6; elevated } \\
\text { neutrophils; } \\
\text { reduced lymphocytes; and low albumin) } \\
\text { Evidence of clinically severe illness with } \\
\text { multisystem ( }>2 \text { ) organ involvement } \\
\text { (cardiac, } \\
\text { kidney, respiratory, hematologic, } \\
\text { gastrointestinal, } \\
\text { dermatologic, or neurological) } \\
\text { AND } \\
\text { No alternative plausible diagnoses } \\
\text { AND } \\
\text { Positive for current or recent SARS-CoV-2 } \\
\text { infection by RT-PCR, serology, or antigen } \\
\text { test; or COVID-19 exposure within the } 4 \text { wk } \\
\text { prior to the onset of symptoms } \\
\text { Some individuals may fulfill full or partial } \\
\text { criteria for Kawasaki disease }\end{array}$ \\
\hline
\end{tabular}

APTT activated partial thromboplastin time; COVID-19 coronavirus disease 2019; CRP C-reactive protein; ECHO echocardiography; ESR erythrocyte sedimentation rate; $M I S-C$ multisystem inflammatory syndrome in children; $N T$-proBNP N-terminal pro-B-type natriuretic peptide; $P T$ prothrombin time; $R T$-PCR reverse transcriptase-polymerase chain reaction; SARS-CoV-2 severe acute respiratory syndrome coronavirus 2

${ }^{a}$ Criteria for Kawasaki disease include persistent fever and four of five principal clinical features: erythema and cracking of lips, strawberry tongue, and/or erythema of oral and pharyngeal mucosa; bilateral bulbar conjunctival injection without exudate; rash (maculopapular, diffuse erythroderma); erythema and edema of the hands and feet and/or periungual desquamation; and cervical lymphadenopathy

chemotaxis and activation (CCL3, CCL4, and CDCP1), as well mucosal immune dysregulation (IL-17A, CCL20, CCL28) were reported. Reductions of $\mathrm{mDC} 1$ (mediator of DNA damage checkpoint 1) and non-classical monocytes, including both NK- and T- lymphocytes in peripheral blood is suggesting extravasation to affected tissues. Upregulation of ICAM1 and FcR1 in neutrophil and nonclassical monocytes indicated enhanced antigen presentation and Fc-mediated responses [35].

\section{Other Paediatric Diseases with Similar Features}

A number of characteristics of PIMS-TS/MIS-C resemble Kawasaki Disease (KD), toxic shock syndrome (TSS) and secondary hemophagocytic lymphohistiocytosis/macrophage activation syndrome (SHLS/ MAS) [13]. In this context, we are comparing this disease with other similar diseases, elucidating pathogenicity of this disease and treatment policies in this article.

\section{Kawasaki Disease}

Kawasaki disease (KD) is the primary vasculitis of anonymous etiology in childhood, where medium and 
small sized arteries are mainly affected [36]. The annual frequency of the disease is reported maximum in Japan, with more than 300 per lakh children aged 4 years or less are affected, compared with 25 per lakh children aged 5 years or younger in North America [33, 37]. KD is differentiated by fever, rash, non-purulent conjunctivitis, cervical lymphadenopathy, oral and extremities changes [38], though the association of other organs, such as the liver, lungs, gastrointestinal tract, the central nervous system, and joints are extensively identified [13].

A sub-part of children $(<5 \%)$ with KD associated with shock/ hypotension are identified as 'Kawasaki disease shock syndrome' (KDSS) [38]. These patients are frequently accompanied with myocarditis and need critical care help throughout the acute phase of sickness [39, 40].

Compared with children with classical KD, patients with KDSS are older and they are likely to have extended period of fever, gastrointestinal symptoms, poorly respond to intravenous immunoglobulin (IVIG) therapy, elevated occurrence of coronary artery abnormalities (CAA), aseptic meningitis and prolonged hospital stay [40, 41]. KDSS children are considerably related with leukocytosis, neutrophilia, higher CRP, ESR, procalcitonin, CK-MB, troponin I, creatinine, hepatic enzymes, triglyceride, BNP, IL6 , IL-10, TNF- $\alpha$, IFN- $\gamma$ and D-dimer levels, anemia, hypoalbuminemia, hyponatremia and hypokalemia[40, 41]. It is theorized that shock in KDSS is associated with myocardial dysfunction, systemic capillary leak syndrome and immune dysregulation dependent overproduction of cytokines [40, 41]. The remarkable resemblance between KDSS and PIMS-TS may advise that they are single entity [38].

\section{Similarities with $K D$}

Patients with PIMS-TS/MIS-C may have some of the clinical resemblances of $\mathrm{KD}$, consisting of fever, dilation of conjunctival blood vessels, rash and redness of the oropharynx. Interestingly, these clinical features are reported in many non-specific contagious diseases in childhood [1].

Earlier, CD45RO + (activated or memory) $\mathrm{T}$ cells and cytotoxic CD8 $+\mathrm{T}$ cells were reported to infiltrate in coronary artery aneurysms in patients with lethal acute KD coronary arteritis and hypothesised the presence of an intraepithelial pathogen, possibly viral, responsible for endothelial injury [42]. More recently, evidence of viruslike particles inside the endothelial cells and endothelitis in tissues from COVID-19 patients was presented [43]. Endothelial cell dysfunction owing to viral contamination could likely elucidate the severe systemic impaired microcirculatory function reported in COVID-19 exposed patients.

\section{Dissimilarities with $K D$}

Several dissimilarities are noted between KD and PIMSTS/ MIS-C. First, the entire clinical depiction is different. Every paediatric patient does not show features of KD, and none show all of them. While, most of KD cases appearing in children are less than 5 years of age and mostly at $\sim$ 10 months of age, PIMS-TS/MIS-C affects older children and adolescents [1]. Abdominal pain and/or diarrhoea are more common feature among PIMS-TS/MIS-C patients than in classical KD (average one in three patients) [6]. Though many MIS-C patients presented with mild coronary artery dilation, in spite of their extreme inflammatory evidence none had developed major coronary artery findings, which is unlikely in KD. Another key characteristic is the inflammatory process that emerges to be different between PIMS-TS/MIS-C and KD. IL-1 seems to influence coronary artery inflammation in patients with $\mathrm{KD}$, and IL-1 regulation is necessary to treat earlier refractory $\mathrm{KD}$ cases [44]. On the other hand, MIS-C is believed to be influenced largely by IL- 6 and IL-8 [45].

Different laboratory outcomes that are observed in PIMS-TS/MIS-C, such as leucopenia and very high level of ventricular natriuretic peptide, are not characteristics of $\mathrm{KD}$. Incidence of KD is predominant among Asian children, while children of African descent appear to be at a specific threat of encountering PIMS-TS/MIS-C [4]. No report of PIMS-TS/MIS-C is available from China and Japan [1].

\section{Toxic Shock Syndrome (TSS)}

Toxic Shock Syndrome (TSS) is a distinctive syndrome secondary to the unrestricted trigger of the immune system by "superantigens" proteins that non-specifically excite $\mathrm{T}$ cells, causing immense cytokine release. Bacterial species, such as Staphylococcus aureus and Streptococcus pyogenes, that can generate exotoxins, act as 'superantigens' [13]. Viruses also behave as 'superantigens' [46]. The features of TSS include hypotension, diffuse erythrodermic rash, mucous membrane involvement, and multisystem organ dysfunction (renal, hepatic, hematologic, respiratory, muscular, and neurologic) [47]. TSS is similar to KDSS, but patients with TSS seem to be older (4.6-9 years) than those with KDSS (3-3.4 years) [48].

\section{Secondary Hemophagocytic Lymphohistiocytosis/ Macrophage Activation Syndrome (SHLH/MAS)}

Hemophagocytic lymphohistiocytosis (HLH) is exemplified by vigorous immune response that is unrelenting and self-perpetuated. Primary HLH is secondary to variance in genes that control the degranulation of natural killer (NK) 
cells and cytotoxic CD8 + lymphocytes; causing failure to remove the antigenic stimuli that led to cellular stimulation, developing "cytokine storm" [49, 50]. Increased level of pro-inflammatory cytokines, for example, interferon (IFN)-gamma, IL-18, and IL-1, consequently stimulate other cells of the immune system (i.e., macrophages), causing organ damage [50]. HLH is believed to be secondary (SHLH), when it is activated by an autoimmune or autoinflammatory condition (for example, MAS), medications, malignancy or infections (such as viral infections) $[51,52]$.

The presence of hyperferritinemia $(>500 \mathrm{ng} / \mathrm{mL}$ ) with fever is possible indicator of SHLH/MAS, especially $[53,54]$. Patients with SHLH distinctively show systemic inflammation with enhanced levels of CRP, triglycerides, and D-dimer, and organ dysfunction that include coagulopathy, liver failure, CNS dysfunction, and cardiac dysfunction. Conspicuously, the peripheral white blood cell count, platelet count, and ESR appear to be lowered in SHLH [50, 53]. MAS is strongly associated to HLH; and is classified as rheumatologic HLH because of its association with systemic onset juvenile idiopathic arthritis, systemic lupus erythematosus, KD and autoinflammatory disorders. It is possible that SARS-CoV-2 infection might activate this cascade of events among genetically susceptible patients [38].

\section{Dengue Shock Syndrome and Scrub Typhus}

These two diseases are very common in tropical countries like India, but rare in Western World. Both the diseases have some common features with PIMS like fever, erythematous rash, peripheral edema, diarrhea, persistent vomiting and hypotensive shock. Therefore, it is extremely important to appropriately identify patients with PIMS or those tropical diseases [55].

\section{Ethnicity}

The inconsistent burden of infection was accounted among Hispanic/Latino and black/African-American ancestry [45]. Other study also mentioned this disease among African/Afro-Caribbean, South Asian, mixed or other minority ethnic groups [56]. Higher share of patients of African ancestry in another report [4] highlighted alarm on an effect of either social and living conditions or genetic susceptibility. Kawasaki disease is occasionally described in sub-Saharan Africa, yet it is probably more frequent than earlier thought [57]. In the United Kingdom and the United States, a 2.5-time higher occurrence was accounted in children of Asian ancestry than that of European ancestry, while an intermediary 1.5 -fold danger was reported from children of African ancestry [58, 59]. Additionally, African-Americans have been unevenly affected by the covid19 pandemic, also implying an augmented vulnerability to severe SARS-CoV-2 infection [33, 60]. The nonexistence of accounted cases of Kawasaki-like multisystem inflammatory syndrome linked with SARS-CoV-2 infection in Asian countries where the covid-19 pandemic began, and where the occurrence of Kawasaki disease is the highest, is worth mentioning [61]. The lower prevalence of disease in Asian countries (such as Japan and China) than in Western countries (such as the United States, Spain, Italy, France and the UK) [62] has led to assumption concerning disparity in the virus affecting places with PIMS-TS/MIS-C cases or an enhanced susceptibility or genomic variation of these populations; although this is conjectural at present [13].

Overall, this newly identified MIS-C also raised doubts, whether this illness is so uncommon that it is detected only in nations with extremely huge number of cases of COVID-19, but not in nations with less number of cases? Or has the virus changed with time that has affected its pathogenicity? Or has some strategy in specific countries affected the incidence of PIMS-TS/MIS-C (e.g., administration of BCG vaccine during infancy)? Information is presently insufficient [1].

\section{Pathophysiology}

\section{Role of Antibodies}

The pathophysiological mechanism of this disease is sketchy. Some have argued that the disease is not the consequence of acute viral infection, but is a post-infectious condition associated to $\mathrm{IgG}$ antibody ( $\mathrm{Ab}$ )-dependent augmentation of disease. This hypothesis probably has appeared for two key reasons. First, PIMS-TS/ MIS-C disease have delayed in time in comparison to the peak of SARS-CoV-2 infection in at least some countries. Second, children with PIMS-TS/MIS-C are occasionally test antibody positive to SARS-CoV-2 than for virus using nasopharyngeal RT-PCR assay [1].

Most patients with negative for identification of the virus, but positive for antibody against SARS-CoV-2, suggested the involvement of an aberrant development of acquired immunity in this disorder. There is proof from SARS-CoV-1 that antibodies enhances the disease either through antibody augmentation of viral entry or replication [63], else through activating host inflammatory response either using immune complexes formation or direct antitissue or cellular activation. Anti-S antibodies against SARSCoV-1 have been revealed to emphasize inflammation in primates and in human macrophages [64], and 
therefore, probably, antibodies develop against SARSCoV-2 may activate an inflammatory process through an analogous mechanism [12].

However, the existence of antibody to SARS-CoV-2 does not itself involve a post-infectious process, because antibodies may appear during the second week of infection. Furthermore, there is inadequate information concerning the specificity of the antibody analysis carried out in patients with PIMS-TS/MIS-C, which may vary extensively. As SARS-CoV-2 infection extends through a community, causing asymptomatic or mild symptomatic infection in most children, positive antibody tests become common, and childhood control is important to ascertain a relationship between SARS-CoV-2 and a particular disease. Of interest, deterioration due to illness has not been a visible clinical dilemma till date in COVID-19 patients, who are treated with convalescent plasma, as one might argue whether antibody-mediated mechanism is essential for the expansion of severe COVID-19 complications [1].

\section{Cytokine Profile in Children}

Cytokines are vital to the pathophysiology of COVID-19; while few of them are advantageous (type-I interferon, IL7), others appear harmful (IL-1 $\beta,-6$, and TNF- $\alpha$ ) particularly in the perspective of the so-called 'cytokine storm' [65]. Uncontrolled generation of pro-inflammatory mediators contributes to acute respiratory distress syndrome (ARDS) [66]. It seems that aging is related with mild elevated concentration of local and systemic pro-inflammatory cytokines and reduced levels of systemic anti-inflammatory cytokines [67].

In addition, adults with acute COVID-19 are believed to have very dissimilar cytokine profiles from those reported in children. The key contributing characteristics elucidiating this difference included IL-8, a chemokine related with lymphopenia in severe COVID-19 cases [68]. IL-7 was also higher in acute COVID-19 hyperinflammation than in MIS-C, which is engaged in T cell maintenance and related with lymphocyte counts [69]. Moreover, raised IL-6, IL17A, CXCL10 contributed mainly to the 'cytokine storm' [70], but was reported considerably lesser in MIS-C patients, signifying a variation in the causal immunopathology [69].

\section{Macrophage Activation Syndrome}

Another assumption on the pathogenesis of PIMS-TS/MIS$\mathrm{C}$ is generation of Macrophage activation syndrome (MAS) in the course of COVID-19 in children, similar to MAS expression observed in adult severe COVID-19 and/or KD [38]. Macrophages are innate immune cells that sense and react to contagions by generating a plethora of inflammatory molecules and by relating with other inflammatory cells. Macrophages are dissimilar in children compared to adults. It is most aptly that macrophages heterogeneity is responsible in determining the severity [71]. Interestingly, no extra viral pathogen was reported by multiplex PCR array. These observations implied that SARS-COV-2 probably activate post-infectious inflammatory disease. Viral elements have been reported in endothelial cells contaminated by SARS-CoV-2, and also an accretion of inflammatory cells, apoptosis and pyroptosis [43]. SARS-CoV-2-epithelial injury at initial phase may stimulate secondary local endothelitis, which may elucidate a delayed auto-inflammatory vasculitic phenotype with upregulation of IL- $1 \beta$ or IL- 6 , for example in KD models [72, 73]. The distinct 'cytokine storm' countenanced by children with PIMS-TS/MIS-C developed from the well-recognized potential of coronaviruses to obstruct type I and type III interferon responses [74], with the possible result of delayed 'cytokine storm' in patients with immune responses that cannot regulate viral replication appropriately, or in those begin with soaring SARS-CoV-2 viral load [74, 75] (Fig. 1).

In this context, the discordance between IL-1 and IL-6 levels is worth mentioning, as generation of IL-1 and IL-6 are related in many infectious and inflammatory processes. Numerous viruses are reported to enhance IL-6 levels directly, either by increasing IL-6 mRNA transcription, or by stabilization of IL-6 mRNA [76]. In addition, the S-protein from an allied virus identified in 2003, SARS$\mathrm{CoV}$, has been shown to stimulate enhanced IL-6 levels in murine macrophage and lung epithelial cell cultures [77, 78].

Onset of the disease emerges 2-4 weeks after acute SARS-CoV-2 infection or contact [6]. As the virus may be primarily replicating in the gastrointestinal tract, enterocytes have been shown to be immediately infected by SARS-CoV-2 [79]. An in-depth scrutiny advocates activation and involvement of neutrophils during PIMS-TS with compensatory contraction of the response and contraregulation of neutrophil phenotype during recovery [80].

Immune dysregulation in adults with respiratory disease is portrayed by lymphopenia (specifically NK cells, CD4 T lymphocytes and B lymphocytes) and continued generation of pro-inflammatory cytokines, such as tumor necrosis factor (TNF)- $\alpha$ and IL-6 [81]. A post-infectious process with delayed immune triggering directing to a cytokine burst, accountable for fever, skin rash, cardiac failure and a major inflammatory syndrome (Fig. 1), which seems parallel to the assumed pathophysiology of 'classical' KD [82, 83]. 


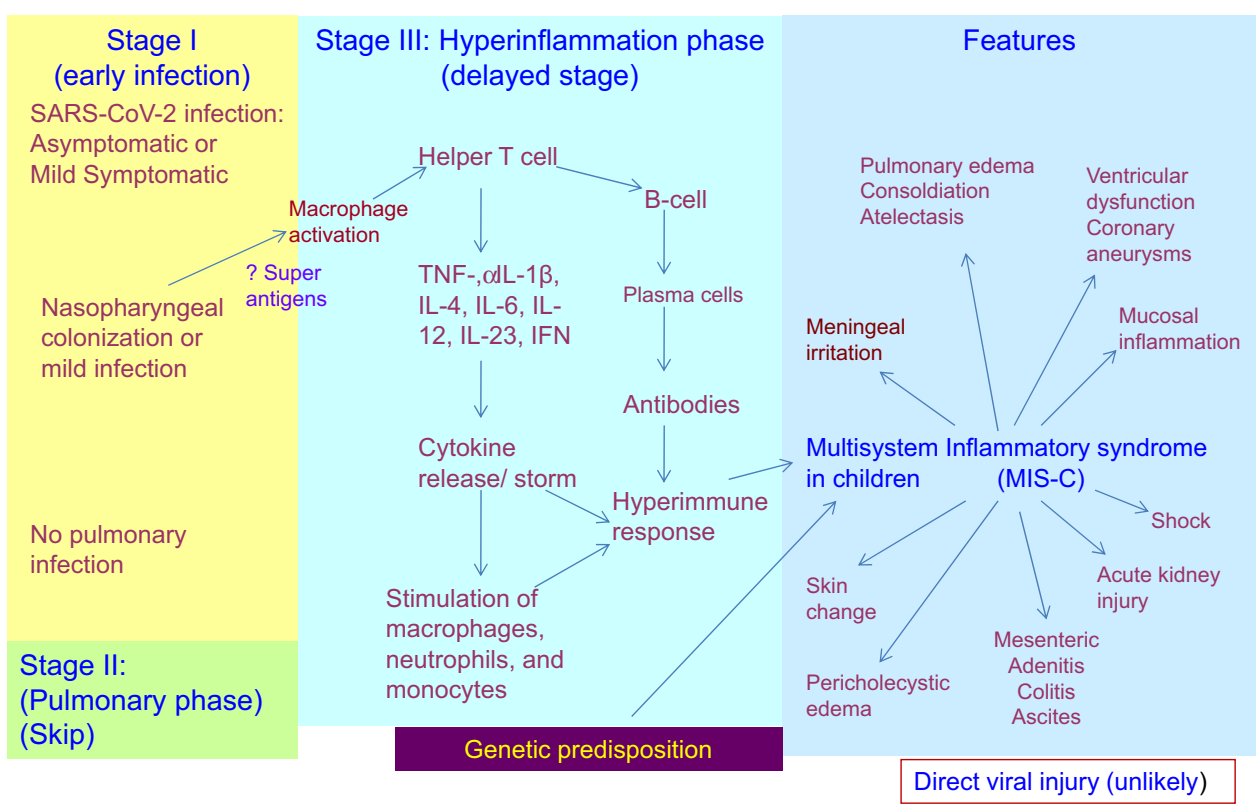

Fig. 1 Pathogenesis of Paediatric Inflammatory Multisystem Syndrome Temporally Associated with SARS-CoV-2 infection (PIMSTS)/ Multisystem Inflammatory Syndrome in Children (MIS-C). Early infection (phase I) with SARS-CoV-2 is possibly to be asymptomatic or mildly symptomatic in children. The pulmonary phase (phase II) is severe in adults but is mild or absent in most

\section{Protection of Children from SARS-COV -2 Infection and Severe COVID-19}

The mechanisms underlying the relative resistance of children to SARS-CoV-2 infection and consequent ailment are imprecisely known and perhaps multifactorial. The lining of the respiratory and gastro-intestinal system, with the surrounding environment and secretions, are the prime defense against viral access, subsequently the innate immune response [7]. Children are vulnerable to viral airway illness. Most children catch a seasonal coronavirus infection at their early age [84]. As coronavirus frequently infect the upper respiratory infection in children, protective measures of antibodies from other coronavirus infections against SARS-CoV-2 should be judged [85]. Interestingly, titres of antibodies to seasonal $\mathrm{CoVs}$ diminish with age, largely in persons above 60 years [84]. This surveillance implies that high titres of anti-seasonal $\mathrm{CoV}$ antibodies or co-infections with other respiratory viruses trigger innate immune responses in children and endorse early and efficient SARS-CoV2 exclusion resulting in mild or asymptomatic courses $[66,86]$. The innate antiviral response stimulates and potentiates the following adaptive immune responses against the virus [7].

In addition, SARS-CoV-2 defense in the pathobiology of COVID-19 in children specifically associated with agerelated angiotensin-converting enzyme-2 (ACE-2) receptor affected children. The early infection seems to activate macrophage followed by the stimulation of T-helper cells. This in turn leads to 'cytokine storm' leading to a hyperimmune response (stage III). This immune dysregulation is related to inflammatory syndrome in affected children. Direct infection by SARS-CoV-2 virus is unlikely to involve in PIMS-TS/ MIS-C

expression, trained immunity, immunosenescence and exhaustion.

\section{Angiotensin-Converting Enzyme-2 (ACE-2) Receptor}

Angiotensin converting enzyme-2 (ACE-2, EC 3.4.17.23) is a counter-regulatory enzyme of renin-angiotensin system (RAS) that acts by translating angiotensin-2 (Ang II) to Ang-(1-7). In normal physiological state, ACE-2 activity sustains homeostasis between Ang II (vasoconstriction, inflammation, fibrosis and proliferation) and Ang-(1-7) pathways (vasodilatation, anti-apoptotic, anti-fibrosis, and anti-proliferation). After entering pneumocytes, SARSCoV-2 reduces ACE-2 activity, lowering Ang II metabolism. This process can drive Ang II-AT1R-dependent elevated pulmonary vascular permeability and inflammation, hence worsening the lung injury [87].

The expression of the ACE- 2 receptor varies between children and adults. The initial contact between SARSCoV-2 and the host occurs in the nasal epithelium. Appreciably lower ACE-2 receptor gene expression in nasal epithelium of children than in older [88], likely protects children from SARS-CoV-2 infection. In contrary, the ACE2 receptor is expressed at a higher level in the lower respiratory tract of children aged below 10 years compared to older subjects [89]. Reduced ACE2 expression in the lower respiratory tract can be an indication of 
severe acute respiratory distress and lung injury, implying a defensive role of ACE-2 in severe lung injury by limiting Ang II-dependent pulmonary capillary leak and inflammation [90]. With the accessible evidence, it is intricate to establish which consequence of lung ACE-2 activity is more imperative in SARS-CoV-2 infection i.e., defense against inflammation mediated lung injury or augmented lung injury by aiding virus entry. However, it seems, ACE2 play twin role: such as a viral receptor and a protective agent in acute lung injury [7].

\section{Trained Immunity}

The innate immune system is vital in children to regulate disturbances in homeostasis, including infections, as adaptive immunity remains under-develop by then. Longterm functional re-programming of innate immune cells, such as myeloid cells and natural killer (NK) cells, to a more activated condition after initial antigen stimulation (infections or vaccination) following metabolic re-programming and epigenetic alterations (acetylation and demethylation leading to enhanced transcription of IL-1 $\beta$, IL-6 and TNF- $\alpha$ genes) is documented as trained immunity (Fig. 1) [91]. Trained immunity owing to scheduled vaccination (Bacille Calmette-Guerin) including live vaccines (against measles, mumps, rubella, and influenza) and recurrent viral infections could be a key shielding means against SARS-CoV-2 contagion in children, although this defensive effect is unlikely to last beyond 1-2 years [7].

\section{Immunosenescence and Exhaustion}

T-lymphocytes are critical in defense during viral infections. CD4 + T-lymphocytes are useful cytokine producers that again stimulate the immune response and assist B-lymphocyte in antibody production and Ig class switching; whereas, cytotoxic CD8 $+\mathrm{T}$ cells kill virusinfected cells and control further virus multiplication. SARS-CoV-2 infection causes peripheral blood (CD4 + and CD8 +) lymphopenia, a process which is probably controlled by the initiation of homing factors and widespread apoptosis/cell death by IL-6 and Fas-FasL interactions. $\mathrm{CD} 8+\mathrm{T}$ lymphocytes are influenced more than $\mathrm{CD} 4+\mathrm{T}$ lymphocytes [92]. In contrast, $\mathrm{T}$ lymphocyte tally remain normal or a little higher in patients with mild disease [93]. T lymphocytes in severe COVID-19 are more stimulated and may display a trend to exhaustion indicating an impaired function [94].

Another risk factor for severity and mortality in COVID-19 in adult compared to children may relate to the process called immunosenescence- a steady decline of the immune system because of aging. The adaptive immune system is more exaggerated than the innate immune system
[95]. One of the essential aspects of immunosenescence is the failure of a functional thymus from a succeeding decline in naïve $\mathrm{T}$ lymphocyte production [96, 97]. These functional impairments are responsible for defective immune responses to infections and impaired vaccination responses in the elderly.

\section{Treatment}

Children suffering from PIMS-TS/MIS-C, need quick and vigorous respiratory, antibiotic, vasopressor and fluid therapy [38]. However, depending on organ system involvement, the specialists from pediatric intensive care, cardiology, rheumatology, infectious disease, immunology, and neurology should be prioritized [13]. Children, who develop shock (myocardial dysfunction) require inotropic/vasoactive drug support (e.g. epinephrine, milrinone, dobutamine, and norepinephrine) and fluid resuscitation [12, 31]. Most patients require immunomodulatory therapy that included intravenous immunoglobulin (IVIg $2 \mathrm{~g} / \mathrm{kg}$ ) with or without anti-inflammatory agents (corticosteroid, tocilizumab) and heparin [8, 10, 31, 33].

Treatment with anakinra may be chosen for patients with KD-like disease, who are refractory to first-line therapy with IVIG (with or without the addition of corticosteroids) [98]. Tocilizumab, an IL-6 inhibitor, has been recommended in the setting of refractory KD [99]. Indian PIMS-TS/ MIS-C Patients responded well to the treatment with tocilizumab [16].

One study recommended infliximab for TNF- $\alpha$ blockade to address PIMS-TS/MIS-C. It has been reported that fever, tachycardia and hypotension in such cases resolved within hours of infliximab treatment. Cytokine profile improved with normalization of TNF- $\alpha$, and decrease in IL- 6 , and IL8 activities. However, the role of anti-TNF agents in such patients requires further investigation [100].

\section{Future Directions}

Elucidating the pathogenesis of PIMS-TS/MIS-C is important for rational management strategies and probable anticipatory measures. More robust clinical information is needed in understanding the risk factors for the development of PIMS-TS/MIS-C, as well as prognosis. It has been assumed that PIMS-TS/MIS-C is an immune mediated post infectious process to SARS-CoV-2. Immunologic studies including serial determination of both cell-mediated and cytokine immune responses can explain insight into pathogenesis. The threat of PIMS-TS/MIS-C depends on the character of the immune response attained, for example, whether the Th1 or Th2 response is predominant. 
Genetic studies are important to recognize why some children with SARS-CoV-2 infection ultimately develop PIMS-TS/MIS-C.

\section{Challenges}

The case definition of PIMS-TS/MIS-C as explained by different health regulatory bodies are extremely broad and would be met in many children with acute COVID-19, KD, other viral infection, systemic onset juvenile idiopathic arthritis, and many other infectious and inflammatory conditions of childhood. Such a broad case definition may likely complicate the identification of the true spectrum and potential complications of MIS-C.

\section{Conclusion}

The enhanced occurrence of PIMS-TS/MIS-C advocates a delayed hyperimmune response to SARS-CoV-2 infection. The precise prevalence of PIMS-TS/MIS-C following an asymptomatic or mild symptomatic infection with SARSCoV-2 is unknown. The question remains if KawaCOVID-19 paediatric patients exhibit a particular cytokine imbalance and immune dysregulation in comparison to adult COVID-19 individuals, and if fundamental genetic factors of vulnerability may affect some children more than others to such inflammatory ailment. More information in understanding the predisposing factors and pathogenesis of PIMS-TS/MIS-C are necessary to suitably prevent and optimally control this circumstance.

\section{Declarations}

Conflict of interest The authors declare that they have no conflict of interest.

\section{References}

1. Rowley AH. Understanding SARS-CoV-2-related multisystem inflammatory syndrome in children. Nat Rev Immunol. 2020;20(8):453-4.

2. Jones VG, Mills M, Suarez D, Hogan CA, Yeh D, Segal JB, et al. COVID-19 and Kawasaki disease: novel virus and novel case. Hosp Pediatr. 2020;10:537-40.

3. Davies P, Evans C, Kanthimathinathan HK, Lillie J, Brierley J, Waters $\mathrm{G}$, et al. Intensive care admissions of children with paediatric inflammatory multisystem syndrome temporally associated with SARS-CoV-2 (PIMS-TS) in the UK: a multicentre observational study. Lancet Child Adolesc Health. 2020;4(9):669-77.

4. Riphagen S, Gomez X, Gonzalez-Martinez C, Wilkinson N, Theocharis P. Hyperinflammatory shock in children during COVID-19 pandemic. Lancet. 2020;395:1607-8.
5. Verdoni L, Mazza A, Gervasoni A, Martelli L, Ruggeri M, Ciuffreda M, et al. An outbreak of severe Kawasaki-like disease at the Italian epicentre of the SARS-CoV-2 epidemic: an observational cohort study. Lancet. 2020;395(10239):1771-8.

6. Pouletty M, Borocco C, Ouldali N, Caseris M, Basmaci R, Lachaume $\mathrm{N}$, et al. Paediatric multisystem inflammatory syndrome temporally associated with SARS-CoV-2 mimicking Kawasaki disease (Kawa-COVID-19): a multicentre cohort. Ann Rheum Dis. 2020;79(8):999-1006.

7. Suratannon N, Dik WA, Chatchatee P, Hagen PMV. COVID-19 in children: Heterogeneity within the disease and hypothetical pathogenesis. Asian Pac J Allergy Immunol. 2020;38(3):170-7.

8. European Centre for Disease Prevention and Control. Rapid risk assessment: Paediatric inflammatory multisystem syndrome and SARS -CoV-2 infection in children. https://www.ecdc.europa. eu/sites/default/files/documents/covid-19-risk-assessment-pae diatric-inflammatory-multisystem-syndrome-15-May-2020.pdf. Updated 2020. (Accessed 16 May 2020).

9. The Centers for Disease Control and Prevention (CDC). Multisystem inflammatory syndrome in children (MIS-C) associated with Coronavirus disease 2019 (COVID-19), 2020. https:// emergency.cdc.gov/han/2020/han00432.asp (Accessed 16 June 2020).

10. Belhadjer Z, Méot M, Bajolle F, Khraiche D, Legendre A, Abakka S, et al. Acute heart failure in multisystem inflammatory syndrome in children (MIS-C) in the context of global SARSCoV-2 pandemic. Circulation. 2020;142(5):429-36.

11. Health Advisory: Pediatric Multi-System Inflammatory Syndrome Temporally Associated with COVID-19 Interim Case Definition in New York State. Available online: https://health. ny.gov/press/releases/2020/docs/2020-05-13_health_advisory. pdf (Accessed 13 May 2020).

12. Whittaker E, Bamford A, Kenny J, Kaforou M, Jones CE, Shah $\mathrm{P}$, et al. Clinical characteristics of 58 children with a pediatric inflammatory multisystem syndrome temporally associated with SARS-CoV-2. JAMA. 2020;324(3):259-69.

13. Nakra NA, Blumberg DA, Herrera-Guerra A, Lakshminrusimha S. Multi-system inflammatory syndrome in children (MIS-C) following SARS-CoV-2 infection: review of clinical presentation, hypothetical pathogenesis, and proposed management. Children (Basel). 2020;7(7):E69.

14. Moreno-Galarraga L, Urretavizcaya-Martínez M, Alegría Echauri J, García Howard M, Ruperez García E, AguileraAlbesa $\mathrm{S}$, et al. SARS-CoV-2 infection in children requiring hospitalization: the experience of Navarra. Spain World J Pediatr. 2020;16(6):614-22.

15. Shahbaznejad L, Navaeifar MR, Abbaskhanian A, Hosseinzadeh F, Rahimzadeh G, Rezai MS. Clinical characteristics of 10 children with a pediatric inflammatory multisystem syndrome associated with COVID-19 in Iran. BMC Pediatr. 2020;20(1):513.

16. Balasubramanian S, Nagendran TM, Ramachandran B, Ramanan AV. Hyper-inflammatory syndrome in a child with COVID19 treated successfully with intravenous immunoglobulin and tocilizumab. Indian Pediatr. 2020;57(7):681-3.

17. Acharyya BC, Acharyya S, Das D. Novel coronavirus mimicking Kawasaki Disease in an infant. Indian Pediatr. 2020;57(8):753-4.

18. Dong Y, Mo X, Hu Y, Qi X, Jiang F, Jiang Z, et al. Epidemiology of COVID-19 among children in China. Pediatrics. 2020;145(6):e20200702.

19. Godfred-Cato S, Bryant B, Leung J, Oster ME, Conklin L, Abrams J, et al. COVID-19-Associated multisystem inflammatory syndrome in children-United States, March-July 2020. MMWR Morb Mortal Wkly Rep. 2020;69(32):1074-80. 
20. https://www.medicaleconomics.com/view/coronavirus-casenumbers-in-the-united-states-july-29-update (Accessed 13 Nov 2020)

21. Zimmermann P, Curtis N. Coronavirus infections in children including COVID-19: An overview of the epidemiology, clinical features, diagnosis, treatment and prevention options in children. Pediatr Infect Dis J. 2020;39(5):355-68.

22. Akca UK, Kesici S, Ozsurekci Y, Aykan HH, Batu ED, Atalay E, et al. Kawasaki-like disease in children with COVID-19. Rheumatol Int. 2020;40(12):2105-15.

23. Ahmed M, Advani S, Moreira A, Zoretic S, Martinez J, Chorath $\mathrm{K}$, et al. Multisystem inflammatory syndrome in children: a systematic review. EClinicalMedicine. 2020;26:100527.

24. Kaushik A, Gupta S, Sood M, Sharma S, Verma S. A systematic review of multisystem inflammatory syndrome in children associated with SARS-CoV-2 infection. Pediatr Infect Dis J. 2020;39(11):e340-6.

25. Wu Z, McGoogan JM. Characteristics of and important lessons from the coronavirus disease 2019 (COVID-19) outbreak in China: summary of a report of 72314 cases from the Chinese Center for Disease Control and Prevention. JAMA. 2020;323:1239-42.

26. Coronavirus Disease 2019 (COVID-19). Available at: https:// www.cdc.gov/coronavirus/2019-ncov/covid-data/covidview/ 04102020/labs-regions.html. (Accessed on 14 Apr 2020)

27. World Health Organization. Multisystem inflammatory syndrome in children and adolescents with COVID-19. Published May 15, 2020. https://www.who.int/publications-detail/multi system-inflammatorysyndrome-in-children-and-adolescentswithcovid-19 (Accessed 22 May 2020)

28. Royal College of Paediatrics and Child Health. Guidance: paediatric multisystem inflammatory syndrome temporally associated with COVID-19. https://www.rcpch.ac.uk/resources/ guidance-paediatric-multisysteminflammatory-syndrome-tempo rally-associatedcovid-19 (Accessed 22 May 2020)

29. Centers for Disease Control and Prevention. Emergency preparedness and response: health alert network. Published May 14, 2020. https://www.emergency.cdc.gov/han/2020/han00432. asp(Accessed 22 May 22 2020)

30. Chiotos K, Bassiri H, Behrens EM, Blatz AM, Chang J, Diorio $\mathrm{C}$, et al. Multisystem inflammatory syndrome in children during the coronavirus 2019 pandemic: a case series. J Pediatric Infect Dis Soc. 2020;9(3):393-8.

31. Grimaud M, Starck J, Levy M, Marais C, Chareyre J, Khraiche $\mathrm{D}$, et al. Acute myocarditis and multisystem inflammatory emerging disease following SARS-CoV-2 infection in critically ill children. Version 2. Ann Intensive Care. 2020;10(1):69.

32. Regev T, Antebi M, Eytan D, Shachor-Meyouhas Y, Ilivitzki A, Aviel YB, et al. Pediatric inflammatory multisystem syndrome with central nervous system involvement and hypocomplementemia following SARS-COV-2 infection. Pediatr Infect Dis J. 2020;39(8):e206-7.

33. Toubiana J, Poirault C, Corsia A, Bajolle F, Fourgeaud J, Angoulvant $\mathrm{F}$, et al. Kawasaki-like multisystem inflammatory syndrome in children during the covid-19 pandemic in Paris, France: prospective observational study. BMJ. 2020;369:m2094.

34. Rauf A, Vijayan A, John ST, Krishnan R, Latheef A. Multisystem inflammatory syndrome with features of atypical Kawasaki disease during COVID-19 Pandemic. Indian J Pediatr. 2020;87(9):745-7.

35. Gruber C, Patel R, Trachman R, Lepow L, Amanat F, Krammer $\mathrm{F}$, et al. Mapping systemic inflammation and antibody responses in multisystem inflammatory syndrome in children (MIS-C). Cell. 2020;183(4):982-995.e14.

36. Schnabel A, Hedrich CM. Childhood Vasculitis. Front Pediatr. 2019;6:421.
37. Makino N, Nakamura Y, Yashiro M, Kosami K, Matsubara Y, Ae R, et al. Nationwide epidemiologic survey of Kawasaki disease in Japan, 2015-2016. Pediatr Int. 2019;61:397-403.

38. Ng KF, Kothari T, Bandi S, Bird PW, Goyal K, Zoha M, et al. COVID-19 multisystem inflammatory syndrome in three teenagers with confirmed SARS-CoV-2 infection. J Med Virol. 2020;92(11):2880-6.

39. Kanegaye JT, Wilder MS, Molkara D, Frazer JR, Pancheri J, Tremoulet AH, et al. Recognition of a Kawasaki disease shock syndrome. Pediatrics. 2009;123:e783-9.

40. Li Y, Zheng Q, Zou L, Wu J, Guo L, Teng L, et al. Kawasaki disease shock syndrome: clinical characteristics and possible use of IL-6, IL-10 and IFN- $\gamma$ as biomarkers for early recognition. Pediatr Rheumatol Online J. 2019;17:1.

41. Ma L, Zhang YY, Yu HG. Clinical manifestations of kawasaki disease shock syndrome. Clin Pediatr (Phila). 2018;57(4):428-35.

42. Brown TJ, Crawford SE, Cornwall ML, Garcia F, Shulman ST, Rowley AH. CD8 T lymphocytes and macrophages infiltrate coronary artery aneurysms in acute Kawasaki disease. J Infect Dis. 2001;184(7):940-3.

43. Varga Z, Flammer AJ, Steiger P, Haberecker M, Andermatt R, Zinkernagel AS, et al. Endothelial cell infection and endotheliitis in COVID-19. Lancet. 2020;395(10234):1417-8.

44. Dusser P, Koné-Paut I. IL-1 inhibition may have an important role in treating refractory Kawasaki disease. Front Pharmacol. 2017;8:163.

45. Riollano-Cruz M, Akkoyun E, Briceno-Brito E, Kowalsky S, Posada R, Sordillo EM, et al. Multisystem inflammatory syndrome in children (MIS-C) related to COVID-19: a New York City experience. J Med Virol. 2020. https://doi.org/10.1002/jmv. 26224.

46. Li Y, Luo C, Li W, Xu Z, Zeng C, Bi S, et al. Structure-based preliminary analysis of immunity and virulence of SARS coronavirus. Viral Immunol. 2004;17:528-34.

47. Chuang YY, Huang YC, Lin TY. Toxic shock syndrome in children: Epidemiology, pathogenesis, and management. Paediatr Drugs. 2005;7:11-25.

48. Lin YJ, Cheng MC, Lo MH, Chien SJ. Early differentiation of Kawasaki disease shock syndrome and toxic shock syndrome in a pediatric intensive care unit. Pediatr Infect Dis J. 2015;34:1163-7.

49. Henderson LA, Canna SW, Schulert GS, Volpi S, Lee PY, Kernan KF, et al. On the alert for cytokine storm: immunopathology in COVID-19. Arthritis Rheumatol. 2020;72(7):1059-63.

50. Grom AA, Horne A, De Benedetti F. Macrophage activation syndrome in the era of biologic therapy. Nat Rev Rheumatol. 2016;12:259-68.

51. Simon DW, Halstead ES, Davila S, Kernan KF, Clark RSB, Storch G, et al. DNA viremia is associated with hyperferritinemia in pediatric sepsis. J Pediatr. 2019;213:82-7.

52. Chesshyre E, Ramanan AV, Roderick MR. Hemophagocytic lymphohistiocytosis and infections: an update. Pediatr Infect Dis J. 2019;38:e54-6.

53. Halyabar O, Chang MH, Schoettler ML, Schwartz MA, Baris EH, Benson LA, et al. Calm in the midst of cytokine storm: A collaborative approach to the diagnosis and treatment of hemophagocytic lymphohistiocytosis and macrophage activation syndrome. Pediatr Rheumatol Online J. 2019;17:7.

54. Schram AM, Campigotto F, Mullally A, Fogerty A, Massarotti E, Neuberg D, et al. Marked hyperferritinemia does not predict for HLH in the adult population. Blood. 2015;125:1548-52.

55. Rajapakse S. Dengue shock. J Emerg Trauma Shock. 2011;4(1):120-7. 
56. Ramcharan T, Nolan O, Lai CY, Prabhu N, Krishnamurthy R, Richter AG, et al. Paediatric inflammatory multisystem syndrome: temporally associated with SARS-CoV-2 (PIMS-TS): cardiac features, management and short-term outcomes at a UK tertiary paediatric hospital. Pediatr Cardiol. 2020;12:1-11. https://doi.org/10.1007/s00246-020-02391-2.

57. Noorani M, Lakhani N. Kawasaki disease: two case reports from the Aga Khan Hospital Dar es Salaam-Tanzania. BMC Pediatr. 2018;18:334.

58. Holman RC, Belay ED, Christensen KY, Folkema AM, Steiner CA, Schonberger LB. Hospitalizations for Kawasaki syndrome among children in the United States, 1997-2007. Pediatr Infect Dis J. 2010;29:483-8.

59. Gardner-Medwin JM, Dolezalova P, Cummins C, Southwood TR. Incidence of Henoch-Schönlein purpura, Kawasaki disease, and rare vasculitides in children of different ethnic origins. Lancet. 2002;360:1197-202.

60. Yancy CW. COVID-19 and African Americans. JAMA. 2020;323(19):1891-2.

61. Lu X, Zhang L, Du H, Zhang J, Li YY, Qu J, et al. SARS-CoV-2 Infection in Children. N Engl J Med. 2020;382:1663-5.

62. Mallapaty S. Will antibody tests for the coronavirus really change everything? Nature. 2020;580:571-2.

63. Katzelnick LC, Gresh L, Halloran ME, Mercado JC, Kuan G, Gordon A, et al. Antibody-dependent enhancement of severe dengue disease in humans. Science. 2017;358(6365):929-32.

64. Liu L, Wei Q, Lin Q, Fang J, Wang H, Kwok H, et al. Anti-spike IgG causes severe acute lung injury by skewing macrophage responses during acute SARS-CoV infection. JCI Insight. 2019;4(4):e123158.

65. Jamilloux Y, Henry T, Belot A, Viel S, Fauter M, El Jammal T, et al. Should we stimulate or suppress immune responses in COVID-19? Cytokine and anti-cytokine interventions. Autoimmun Rev. 2020;19(7):102567.

66. Felsenstein S, Herbert JA, McNamara PS, Hedrich CM. COVID-19: Immunology and treatment options. Clin Immunol. 2020;215:108448.

67. Meftahi GH, Jangravi Z, Sahraei H, Bahari Z. The possible pathophysiology mechanism of cytokine storm in elderly adults with COVID-19 infection: the contribution of "inflame-aging." Inflamm Res. 2020;69(9):825-39.

68. Zhang X, Tan Y, Ling Y, Lu G, Liu F, Yi Z, et al. Viral and host factors related to the clinical outcome of COVID-19. Nature. 2020;583:437-40.

69. Consiglio CR, Cotugno N, Sardh F, Pou C, Amodio D, Rodriguez $\mathrm{L}$, et al. The immunology of multisystem inflammatory syndrome in children with COVID-19. Cell. 2020;183(4):968981.e7.

70. Jia S, Li C, Wang G, Yang J, Zu Y. The T helper type 17/regulatory $\mathrm{T}$ cell imbalance in patients with acute Kawasaki disease. Clin Exp Immunol. 2020;162:131-7.

71. Pagliaro P. Is macrophages heterogeneity important in determining COVID-19 lethality? Med Hypotheses. 2020;143:110073.

72. Armaroli G, Verweyen E, Pretzer C, Kessel K, Hirono K, Ichida $\mathrm{F}$, et al. Monocyte-derived interleukin- $1 \beta$ as the driver of S100A12-induced sterile inflammatory activation of human coronary artery endothelial cells: implications for the pathogenesis of Kawasaki disease. Arthritis Rheumatol. 2019;71:792-804.

73. Nandi A, Pal P, Basu S. A comparison of serum IL6 and CRP levels with respect to coronary changes and treatment response in Kawasaki disease patients: a prospective study. Rheumatol Int. 2019;39:1797-801.
74. Park A, Iwasaki A. Type I and type III interferons-induction, signaling, evasion, and application to combat COVID-19. Cell Host Microbe. 2020;27:870-8.

75. Blanco-Melo D, Nilsson-Payant BE, Liu WC, Uhl S, Hoagland $\mathrm{D}, \mathrm{M} \varnothing l$ ler R, et al. Imbalanced host response to SARS-CoV-2 drives development of COVID-19. Cell. 2020;181(1036-1045):e9.

76. Tanaka T, Narazaki M, Kishimoto T. IL-6 in inflammation, immunity, and disease. Cold Spring Harb Perspect Biol. 2014;6(10):a016295.

77. Wang W, Ye L, Ye L, Li B, Gao B, Zeng Y, et al. Up-regulation of IL-6 and TNF-alpha induced by SARS-coronavirus spike protein in murine macrophages via NF-kappaB pathway. Virus Res. 2007;128(1-2):1-8.

78. Yoshikawa T, Hill T, Li K, Peters CJ, Tseng CT. Severe acute respiratory syndrome (SARS) coronavirus-induced lung epithelial cytokines exacerbate SARS pathogenesis by modulating intrinsic functions of monocyte-derived macrophages and dendritic cells. J Virol. 2009;83(7):3039-48.

79. Lamers MM, Beumer J, van der Vaart J, Knoops K, Puschhof J, Breugem TI, et al. SARS-CoV-2 productively infects human gut enterocytes. Science. 2020;369(6499):50-4.

80. Klocperk A, Parackova Z, Dissou J, Malcova H, Pavlicek P, Vymazal T, et al. Case report: systemic inflammatory response and fast recovery in a pediatric patient with COVID-19. Front Immunol. 2020;11:1665.

81. Giamarellos-Bourboulis EJ, Netea MG, Rovina N, Akinosoglou $\mathrm{K}$, Antoniadou A, Antonakos N, et al. Complex immune dysregulation in COVID-19 patients with severe respiratory failure. Cell Host Microbe. 2020;27(6):992-1000.e3.

82. Wang Y, Qian SY, Yuan Y, Wang Q, Gao L, Chen X, et al. Do cytokines correlate with refractory Kawasaki disease in children? Clin Chim Acta. 2020;506:222-7.

83. Noval Rivas M, Wakita D, Franklin MK, Carvalho TT, Abolhesn A, Gomez AC, et al. Intestinal permeability and IgA provoke immune vasculitis linked to cardiovascular inflammation. Immunity. 2019;51:508-21.

84. Gao X, Zhou H, Wu C, et al. Antibody against nucleocapsid protein predicts susceptibility to human coronavirus infection. J Inf Secur. 2015;71:599-602.

85. Shen C, Wang Z, Zhao F, et al. Treatment of 5 critically ill patients with COVID-19 with convalescent plasma. JAMA. 2020;323(16):1582-9.

86. Hedrich CM. COVID-19- considerations for the paediatric rheumatologist. Clin Immunol. 2020;214:1-3.

87. Das SK. The Pathophysiology, Diagnosis and Treatment of Corona Virus Disease 2019 (COVID-19). Indian J Clin Biochem. 2020;35(4):1-12.

88. Bunyavanich S, Do A, Vicencio A. Nasal gene expression of angiotensin-converting enzyme 2 in children and adults. JAMA. 2020;323(23):2427-9.

89. Ortiz ME, Thurman A, Pezzulo A, Leidinger MR, Klesney-Tait JA, Karp PH, et al. Heterogeneous expression of the SARSCoronavirus-2 receptor ACE2 in the human respiratory tract. EBioMedicine. 2020;60:102976.

90. Gemmati D, Bramanti B, Serino ML, Secchiero P, Zauli G, Tisato V. COVID-19 and individual genetic susceptibility/receptivity: Role of ACE1/ACE2 genes, immunity, inflammation and coagulation. Might the double X-Chromosome in females be protective against SARS-CoV-2 compared to the single X-Chromosome in males? Int J Mol Sci. 2020;21(10):3474.

91. Netea MG, Domínguez-Andrés J, Barreiro LB, Chavakis T, Divangahi M, Fuchs E, et al. Defining trained immunity and its role in health and disease. Nat Rev Immunol. 2020;20(6):375-88. 
92. Diao B, Wang C, Tan Y, Chen X, Liu Y, Ning L, et al. Reduction and functional exhaustion of $\mathrm{T}$ cells in patients with coronavirus disease 2019 (COVID-19). Front Immunol. 2020;11:827.

93. Thevarajan I, Nguyen TH, Koutsakos M, Druce J, Caly L, van de Sandt CE, et al. Breadth of concomitant immune responses prior to patient recovery: a case report of non-severe COVID-19. Nat Med. 2020;26:453-5.

94. Zheng H-Y, Zhang M, Yang C-X, Zhang N, Wang X-C, Yang $\mathrm{X}-\mathrm{P}$, et al. Elevated exhaustion levels and reduced functional diversity of $\mathrm{T}$ cells in peripheral blood may predict severe progression in COVID-19 patients. Cell Mol Immunol. 2020;17(5):541-3.

95. Fulop T, Larbi A, Dupuis G, Le Page A, Frost EH, Cohen AA, et al. Immunosenescence and inflamm-aging as two sides of the same coin: friends or foes? Front Immunol. 2018;8:1960.

96. van den Broek T, Borghans JA, van Wijk F. The full spectrum of human naive T cells. Nat Rev Immunol. 2018;18(6):363-73.
97. Tang F, Quan Y, Xin ZT, Wrammert J, Ma MJ, Lv H, et al. Lack of peripheral memory $\mathrm{B}$ cell responses in recovered patients with severe acute respiratory syndrome: a six-year follow-up study. J Immunol. 2011;186(12):7264-8.

98. Guillaume MP, Reumaux H, Dubos F. Usefulness and safety of anakinra in refractory Kawasaki disease complicated by coronary artery aneurysm. Cardiol Young. 2018;28:739-42.

99. Nozawa T, Imagawa T, Ito S. Coronary-artery aneurysm in tocilizumab-treated children with Kawasaki's disease. N Engl J Med. 2017;377(19):1894-6.

100. Dolinger MT, Person H, Smith R, Jarchin L, Pittman N, Dubinsky MC, et al. Pediatric crohn's disease and multisystem inflammatory syndrome in children (MIS-C) and COVID-19 treated with infliximab. J Pediatr Gastroenterol Nutr. 2020;71(2):153-5.

Publisher's Note Springer Nature remains neutral with regard to jurisdictional claims in published maps and institutional affiliations. 